\title{
A CASE REPORT ON SUBUNGUAL GLOMUS TUMOR WITH ATYPICAL PRESENTATION OF COMPLETE LONGITUDINAL SPLITTING OF NAIL.
}

Yogendra Singh Bhakuni, Arun Bhatnagar, Krishnanand Dhruw, Ashish Kumar Dwivedi
1. Junior Resident. Department of Surgery, Gandhi Medical College.
2. Associate Professor. Department of Surgery, Gandhi Medical College.
3. Senior Resident. Department of Surgery, Gandhi Medical College.
4. Senior Resident. Department of Surgery, Gandhi Medical College.

\section{CORRESPONDING AUTHOR: \\ Yogendra Singh Bhakuni, \\ Plot No.249, C-Sector, \\ Happy Homes Apartment, \\ Flat No. M-1, Indrapuri, Bhopal. \\ Pin Code- 462021. \\ E-mail: dr_yogendranb@yahoo.co.in}

\begin{abstract}
Glomus Tumour is an uncommon, painful entity arising from the arterial end of the glomus body. We report an interesting case of chronic severe obscure pain in the finger tips with the complete longitudinal splitting of nail. Love Test (eliciting point tenderness on pressing the swelling with tip of pen) was positive in our case and the patient had increased sensitivity to cold temperature. Hildreth test (disappearance of the pain after application of a tourniquet proximally on the arm in case of glomus tumour) was negative in our case. Colour Doppler helped to diagnose the presence of mass in subungual area. Patient was treated with the excision of the swelling along with nail. Histopathological finding confirmed the diagnosis of the subungual glomus tumour. Longitudinal splitting of the nail due to underlying glomus tumour is a unique presentation which will help in making clinical diagnosis and examining patient of glomus tumour with such presentation on clinical grounds.
\end{abstract}

INTRODUCTION: An interesting case of subungual glomus tumour causing longitudinal splitting of the nail, resembling median canaliform dystrophy of nail, is being reported. Longitudinal splitting of the nail as seen in median canaliform dystrophy is commonly seen following chronic trauma to the nail or nail bed. However, underlying tumors of the matrix can also cause longitudinal splitting. We report an atypical complete longitudinal splitting of nail due to underlying glomus tumour.

CASE HISTORY: A 22 year old female reported to the Surgical OPD with an exquisitely painful right hand little finger, which was also a complete longitudinal split from the proximal nail bed. She reported that she was apparently alright 8 years ago when she developed pain over right hand little finger nail bed and fingertip which use to radiate over same hand and in last two years patient has developed longitudinal split (Figure no. 1\&2) starting from free end of nail plate. The longitudinal split grew during this period towards proximal nail fold. She complained of severe pain, point tenderness was present as suggested by positive Love test (eliciting tenderness on pressing the point with tip of pen). She also complained of increased sensitivity to cold temperature. There was no history of drug intake or any family history of a similar affliction. There was no history of any repeated trauma or any habit of tic involving 


\section{CASE REPORT}

manipulation of the nail apparatus. Hildreth Test (disappearance of the pain after application of a tourniquet proximally on the arm in case of glomus tumour) was negative in our case.

COLOUR DOPPLER-There is a hypoechoic collection of size 4 x $4 \mathrm{~mm}$ filled with low level internal echoes and no significant internal vascularity located in subungual region of little finger.

MANAGEMENT: Nail bed avulsion done by giving incision over the nail bed and excising the mass by exploring the nail bed and matrix. A small whitish mucoid nodule measuring about $6 \times 3$ $\mathrm{mm}$ was seen in the matrix (Figure no.3 and 4)

HISTOPATHOLOGICAL FINDING: Section shows vascular spaces separated by nests of small round cells with scant cytoplasm. The vessels are closely associated with slender cords.These vascular structures are surrounded by rounded uniform epithelioid cells with granular cytoplasm known as glomus cells or pericytes. Also present are smooth muscle cells and nonmyelinated nerve cells. Findings were suggestive of glomus tumour. There is no pleomorphism or mitotic activity.(Figure no. 5).

DISCUSSION Glomus tumours are usually solitary lesion and presents with symptom complex of pain and tenderness and hypersensitivity on exposure to cold temperature. Most common sites are extremities usually subungual in position. Pain can be severe in nature causing atrophy of the limb too. Longitudinal splitting of nail is also one of the unusual presentation of the Glomus tumour which has been reported in past in one study (2).Benign and malignant tumours like glomus tumour, myxoid cyst, papilloma, squamous cell carcinoma, malignant melanoma, etc., can have a subungual location and can cause nail dystrophy, including longitudinal grooving and lifting of the nail plate from the bed. $(2,9,10)$.

Median canaliform dystrophy of Heller (dystrophia unguis median acanaliformis, nevus striatus unguis), as the name suggests, is a dystrophic condition of the nail in which longitudinal splitting occurs.(2,10)It is almost exclusively seen on the thumbs, and often there is bilateral involvement of thumbnails. The symptoms could go on and off or can remain throughout the life even without any exposure to trauma. That questions the widely supported belief that the entity Is secondary to chronic trauma.(13) Two test/sign has been described for glomus tumor Hildreth sign and Love Test (elicitation of tenderness on touching the site with pen tip). Hildreth's Sign is disappearance of the pain after application of a tourniquet proximally on the arm.

Treatment of choice for glomus tumour is surgical excision and with the introduction of the laser modalities work has become more precise and cosmetically better. Excision should be limited to the symptomatic patients. Subungual glomus tumours are more difficult to treat because they are small, sometimes total eradication requires several procedures. ${ }^{(1,4,5)}$ Local recurrences have been reported to occur in around $2 \%$ of cases.(2,5) In our case pain and symptoms were completely relieved after surgery.

CONCLUSION: It is suggested that glomus tumours should always be kept in mind when considering differential diagnosis of any painful condition of the terminal digit. Subungual solitary glomus tumours (neuromyoarterial tumors) can either be skin colored or bluish. They can also cause concave surface erosions of the underlying bone, seen by a plain x-ray. A complete excision is indicated for relief of pain; however, when present in subungual location, 
their small size makes them difficult at times to be located and eradicated. In our case too, one small tumor measuring $6 \mathrm{~mm} \times 3 \mathrm{~mm}$ was not visible until the nail was avulsed.

\section{REFERENCES-}

1. Case Report on two cases of subungualglomus tumour: PS Murthy, R Rajagopal , PK Gar,S Grover. Indian Journal of Dermatology, Venerology and Leprology. Year 2006,Volume 72,Issue 1,Page:47-49

2. Case report on GlomusTumour- induced longitudinal splitting of nails mimicking median canaliform dystrophy of nails: Indian Journal of Dermatology,Venerology and Leprology:Year 2008,Volume 74,Issue 3,Page:257-259

3. Bhaskaranand K, Navadgi BC. Glomus tumour of the hand. J Hand Surg 2002;27:229-31

4. Dawber RP, Baran R. Disorders of nails. In : Champion RH, Burton JL, Ebling FJG, editors. Rook/Wilkinson/Ebling Textbook of Dermatology. 5th ed. Oxford: Blackwell Science; 1992. p. 2497-532.

5. Heys SD, Brittened J, Atkinson P, EreminO .Glomus tumour: an analysis of 43 patients and review of the literature. Br J Surg 1992;79:345-7

6. Hatori M, Aiba S, Kato M, Kamiya N, Kokuben S. Expression of CD 34 in glomus tumors. Tohoku J Exp Med 1997;182:241-7

7. Kiyosawa T, Umebayashi Y, Nakayama Y, Soeda S. Hereditary multiple glomus tumours involving glans penis. A case report and review of literature. DermatolSurg 1995;21:895-9.

8. Lumley JS, Stansfiels AG. Infiltrating glomus tumour of lower limb. BMJ 1972;1:484-5.

9. GieleH.Hildreth's test is a reliable clinical sign for the diagnosis of glomus tumours. J Hand Surg 2002;27:157-8.

10. Odom R, James W, Berger T. In : Diseases of the skin appendages. Andrew's Diseases of the Skin. $9^{\text {th }}$ ed. Philadelphia: WB Saunders and Co; 2000. p. 984-5.

11. 11)Baran R, de Berker de DA, Dawber R. In nails: Appearance and therapy. $1^{\text {st }}$ ed. London: Martin Dunitz; 1993. p. 16-7.

12. GieleH.Hildreth's test is a reliable clinical sign for the diagnosis of glomus tumours. J Hand Surg 2002;27:157-8.

13. Bottomley WW, Cunliffe WJ. Median nail dystrophy associated with isotretinoin therapy. Br J Dermatol 1992;127:447-8

14. Takata H, Ikuta Y, Ishida O, Kimori K. Treatment of subungualglomus tumour. Hand Surg 2001;6:25-7 


\section{CASE REPORT}

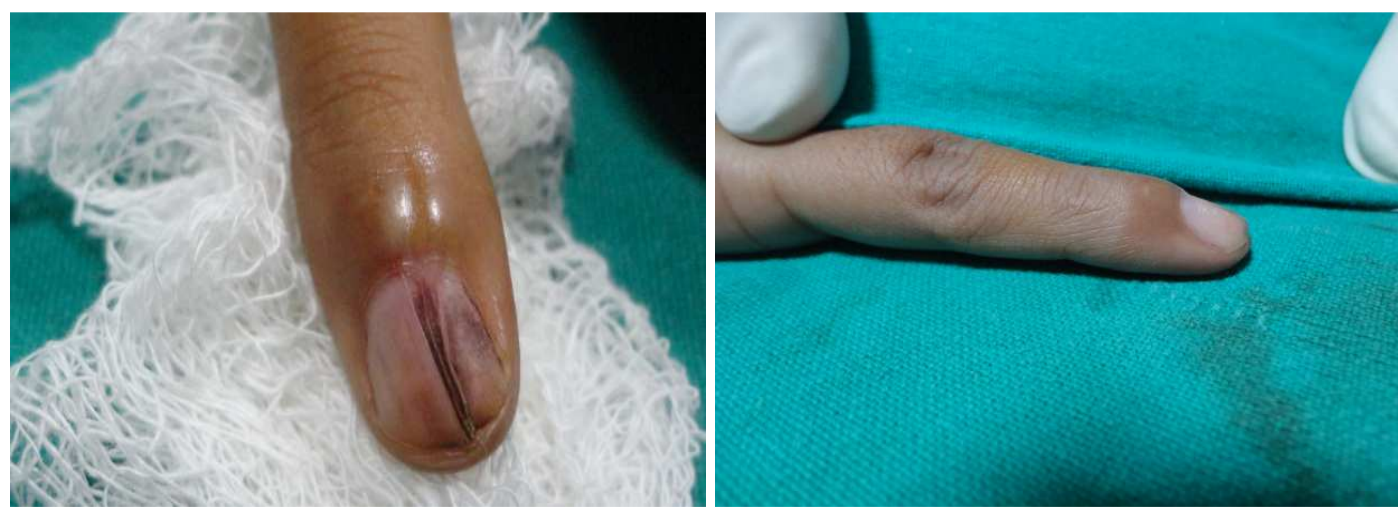

Figure No.1 - 22 year old female showing Figure No. 2 - Lateral View Showing Complete splitting of the Right hand little Swelling at the base of the nail bed Finger nail. of Right hand little finger.
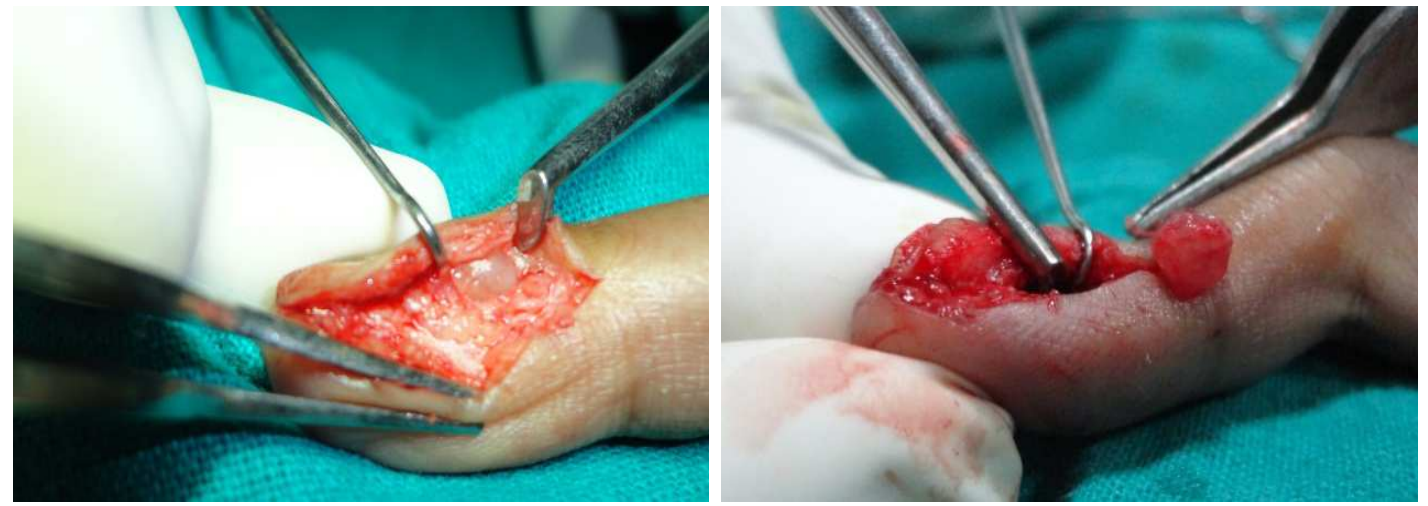

Figure No.3 - Intraoperative picture Figure No.4 - 6x3 mm glomustumour showing incision given along excised from the base ofnail bed nail bed with tumour visible

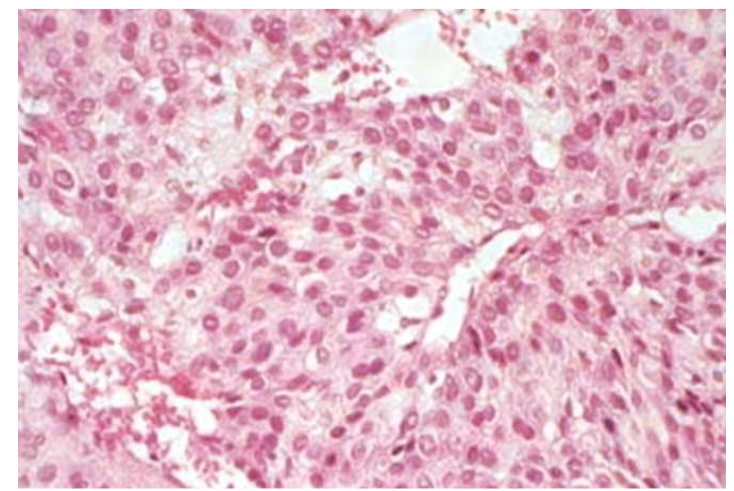

Figure No.5- Histopathological Section showing vascular spaces separated by nests of small round cells with scant cytoplasm. The vascular structures surrounded by rounded uniform epithelioid cells with granular cytoplasm known as glomus cells or pericytes 